\title{
Sinusoidal Obstruction Syndrome (Veno-occlusive Disease) Following Hematopoietic Stem Cell Transplant: Insights and Therapeutic Advances
}

\author{
SAMAH NASSEREDDINE ${ }^{1,2}$, SAUD ALSUBAIT $^{3}$ and IMAD TABBARA ${ }^{1,2}$ \\ ${ }^{1}$ The George Washington University School of Medicine, Washington, DC, U.S.A.; \\ ${ }^{2}$ The George Washington Cancer Center, Washington, DC, U.S.A.; \\ ${ }^{3}$ Greater Danbury Community Health Center, Danbuty, CT, U.S.A.
}

\begin{abstract}
Hepatic sinusoidal obstruction syndrome (SOS) is a rare fatal clinical entity seen following hematopoietic stem cell transplant (HSCT). It is more commonly reported to occur following allogeneic HSCT compared to autologous HSCT. Historically, it is known as hepatitis following HSCT. It is thought that endothelial damage to the hepatic venules leading to occlusion of the terminal hepatic venules and hepatic sinusoids is the trigger for the development of SOS. Several risk factors have been associated with this condition. Some of these risk factors are patient related while others are transplant process related. Given the high mortality of this condition, early identification of high-risk patients with severe disease is of utmost importance. The management of SOS varies depending on the severity of the disease. Mild to moderate disease has a good outcome with supportive measures alone, while severe presentation of the disease requires a more aggressive management. Defibrotide is the only Food and Drug Administration-approved therapy and it is reserved for severe cases of SOS. The role of defibrotide as a prophylactic therapy remains under investigation.
\end{abstract}

Sinusoidal obstruction syndrome (SOS), previously referred to as hepatic veno-occlusive disease, is a rare life-threatening condition. Despite its rarity, it is still amongst the most fatal complications following autologous stem cell transplant

Correspondence to: Imad Tabbara, MD, Professor of Medicine, Director Blood \& Marrow transplant Program, Division of Hematology/Oncology and GW Cancer Center, George Washington University Medical Faculty Associates, 2150 Pennsylvania Avenue, NW, Washington, DC 20037, U.S.A. Tel: +1 2027412478, Fax: +1 202 7412487, email: itabbara@mfa.gwu.edu

Key Words: Stem cell Transplant, SOS, VOD, review.
ASCT (1). The typical presentation is characterized by right upper quadrant pain, hepatomegaly, jaundice and ascites. It can develop at any time following hematopoietic stem cell transplant (HSCT) but classically during the first 3 weeks. The incidence varies between 0 to $60 \%$ in different studies. Children with SOS tend to have higher mortality rate compared to adults (1).

This entity occurs secondary to the release of toxic metabolites during the conditioning phase and direct toxicity from chemotherapy and radiation leading to an injury to the sinusoidal cells and hepatocytes in zone 3 of the hepatic acinus. This phenomenon of endothelial cell (EC) activation creates a prothrombic state leading to the occlusion of hepatic venules and sinusoids (2-4). This review is limited to SOS in adult patients and summarizes the pathophysiology, risk factors, and diagnostic criteria of this condition, as well as discussing therapeutic advances.

\section{Pathophysiology}

The main underlying pathophysiology of SOS is damage to sinusoidal ECs. There are direct causes (e.g. irradiation, chemotherapy and conditioning regimen) and indirect causes (e.g. pre-existing tissue injury, immunosuppressive agent and allogenicity) that play a crucial role in EC injury. Under normal conditions, hepatocytes metabolize drugs such as cyclophosphamide via the cytochrome $P-450$ enzymatic system to toxic metabolites. Glutathione (GSH) enzymatic activity helps transform the toxic metabolites into non-toxic ones, ensuring protection of the liver. Given the poor concentration of GSH and high abundance of P-450 in the centrilobular areas of the liver, there is increased susceptibly to toxic metabolites and higher incidence of SOS commonly in zone 3 of the hepatic acinus of the centrilobular area (36). Figure 1 illustrates this phenomenon. 
In HSCT, patients receive high doses of toxic drugs during the conditioning regimen (e.g. cyclophosphamide and busulfan). This causes initial EC damage leading to graft versus host disease (GVHD), SOS, capillary leak syndrome, engraftment syndrome and diffuse alveolar hemorrhage (2, 4). The damaged ECs secrete cytokines that cause weakness in the mucosal barrier between the ECs, promoting the escape of red blood cells, white blood cells and platelets between the hepatocytes and sinusoid ECs leading to dissection of this layer and the initiation of the inflammatory process $(7,8)$. In addition, there is an increased release and expression of von Willebrand factor, intercellular adhesion molecule-1, vascular adhesion molecule-1, plasminogen activator inhibitor-1 (PAI1), and thrombomodulin as shown in Figure 2. This pro-inflammatory process promotes a prothrombotic state, especially in allogeneic HSCT (9). The cascade of actions and interactions, as well as the activation of the healing mechanism yielding to fibrosis, leads to the obstruction of normal blood flow and increases venous resistance, causing the development of high portal blood pressure, further liver dysfunction and fluid retention in the form of ascites (9-11).

SOS is reported to develop more frequently in allogeneic HSCT compared with autologous HSCT. In allogeneic HSCT, the acute and chronic GVHD are promoted by both humoral and cell-mediated (T-cell) immunity, which may occur in the small bile ducts of the liver, causing injury and damage to these cells, contributing to the elevation of portal system blood pressure and EC damage (9). This is thought to be related to the conditioning regimen and GVHD prophylaxis used during HSCT. Despite the similar immunological background of GVHD and SOS, PAI1 is found to be elevated in SOS but not in $\operatorname{GVHD}(12,13)$. PAI1 might be used in the future as a marker to distinguish between SOS and GVHD in challenging patients. A list of circulating markers in SOS and GVHD are summarized in Table I.

\section{Clinical Presentation and Diagnosis}

Traditionally, SOS was diagnosed according to either the Baltimore or the Seattle criteria as shown in Table II (1). The clinical presentation is related to fluid retention secondary to portal hypertension, manifesting by ascites, painful hepatomegaly, jaundice, encephalopathy, confusion and weight gain. As a result of fluid overload, many organs may be affected, leading to hepatic-pulmonary syndrome, hepatorenal syndrome, and cardiac failure, which will eventually progress to multiple-organ failure with associated high mortality $(9,14)$.

With the evolving understanding of this entity and with the advancement in the strategy of conditioning regimens, the European Group For Blood and Marrow Transplant developed revised diagnostic criteria, highlighting late-onset
Table I. Effects on levels of circulating markers in sinusoidal obstruction syndrome (SOS) and graft versus host disease (GVHD) (3).

\begin{tabular}{lcl}
\hline Marker & SOS/VOD & GVDH \\
\hline vWF & Increase & Increase \\
TM & Increase & Increase \\
PAI1 & Increase & ------- \\
ICAM1 & Increase & Increase \\
ANG2 & ------- & Increase \\
VEGF & Increase & Increase \\
\hline
\end{tabular}

vWF: Von Willebrand factor; ICAM1: intercellular adhesion molecule1; PAI1: plasminogen activator inhibitor-1; TM: thrombomodulin; VEGF: vascular endothelial growth factors; ANG2: angiopoietin 2.

Table II. Clinical criteria for sinusoidal obstruction syndrome (22).

Baltimore Criteria

In the first 21 days after HSCT, the presence of bilirubin $>2 \mathrm{mg} / \mathrm{dl}$ plus two or more of the following:

- Painful hepatomegaly

- Ascites

- Weight gain (>5\% basal weight)

Modified Seattle Criteria

In the first 20 days after HSCT, the presence of

two or more of the following:

- Bilirubin >2 mg/dl.

- Hepatomegaly or pain in RUQ

- Weight gain ( $>2 \%$ basal weight)

RUQ: Right upper quadrent; HSCT: hematopoietic stem cell transplant.

Table III. New criteria of the European Society for Blood and Marrow Transplantation for sinusoidal obstruction syndrome (SOS) (2).

Classical in the first 21 days after HSCT

Bilirubin $\geq 2 \mathrm{mg} / \mathrm{dl}$ plus two or more of the following:

- Painful hepatomegaly

- Ascites

- Weight gain (>5\% basal weight)

Late onset beyond 21 days after HSCT

- Classical SOS beyond 21days.

OR

- Histologically proven SOS.

OR

Two of more of the following criteria must present:

- Bilirubin $>2 \mathrm{mg} / \mathrm{dl}$.

- Painful hepatomegaly

- Weight gain (>5\% basal weight)

- Ascites

AND hemodynamical or ultrasound evidence of SOS 


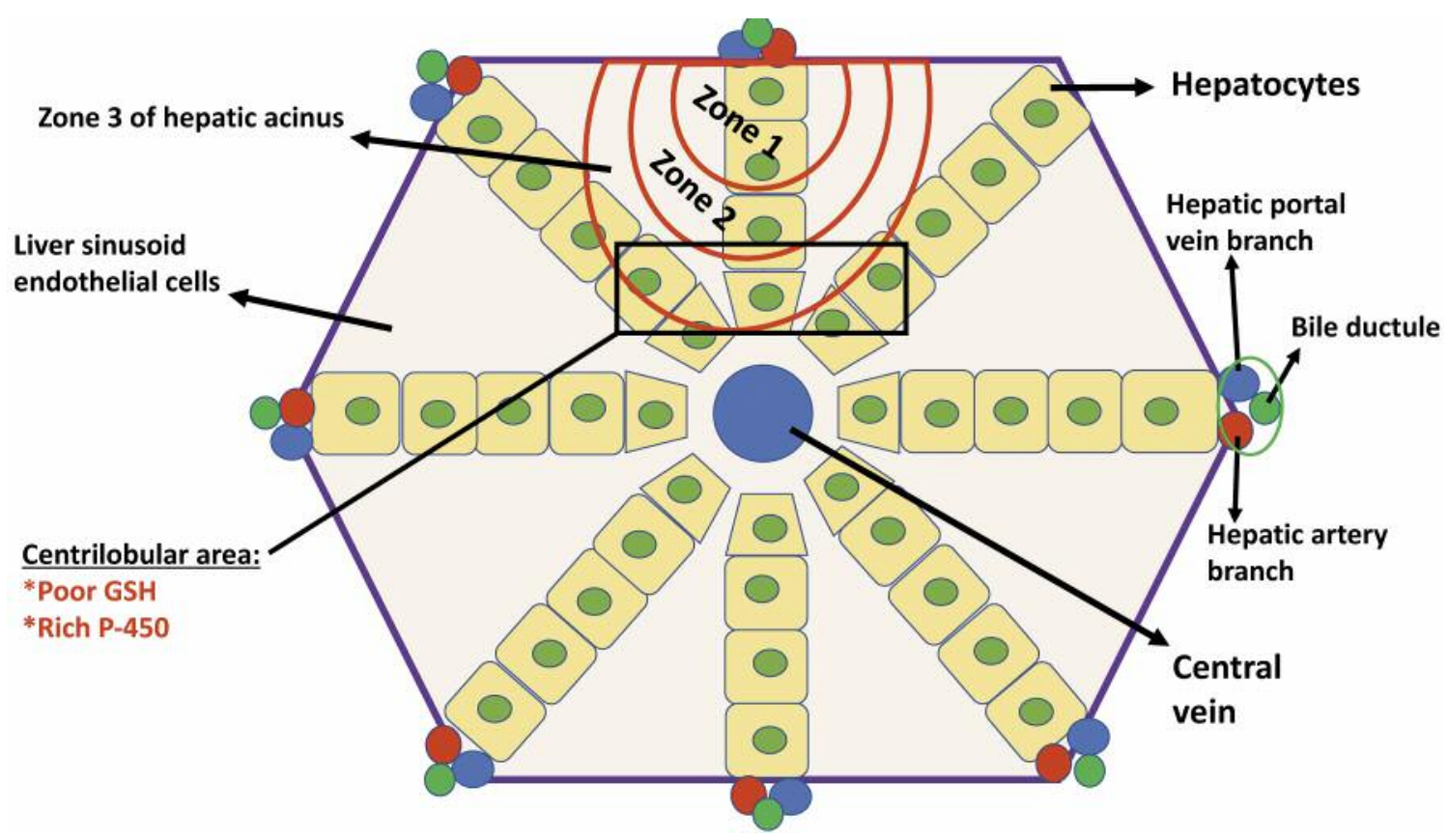

Figure 1. Hepatic acinus. Obstruction of the hepatic sinusoids mainly occurs in zone 3 of the hepatic acinus. The centrilobular area of zone 3 carry poor concentration of glutathione (GSH). glutathione is important in protecting hepatic cells from the toxic metabolites via conversion into nontoxic metabolites.

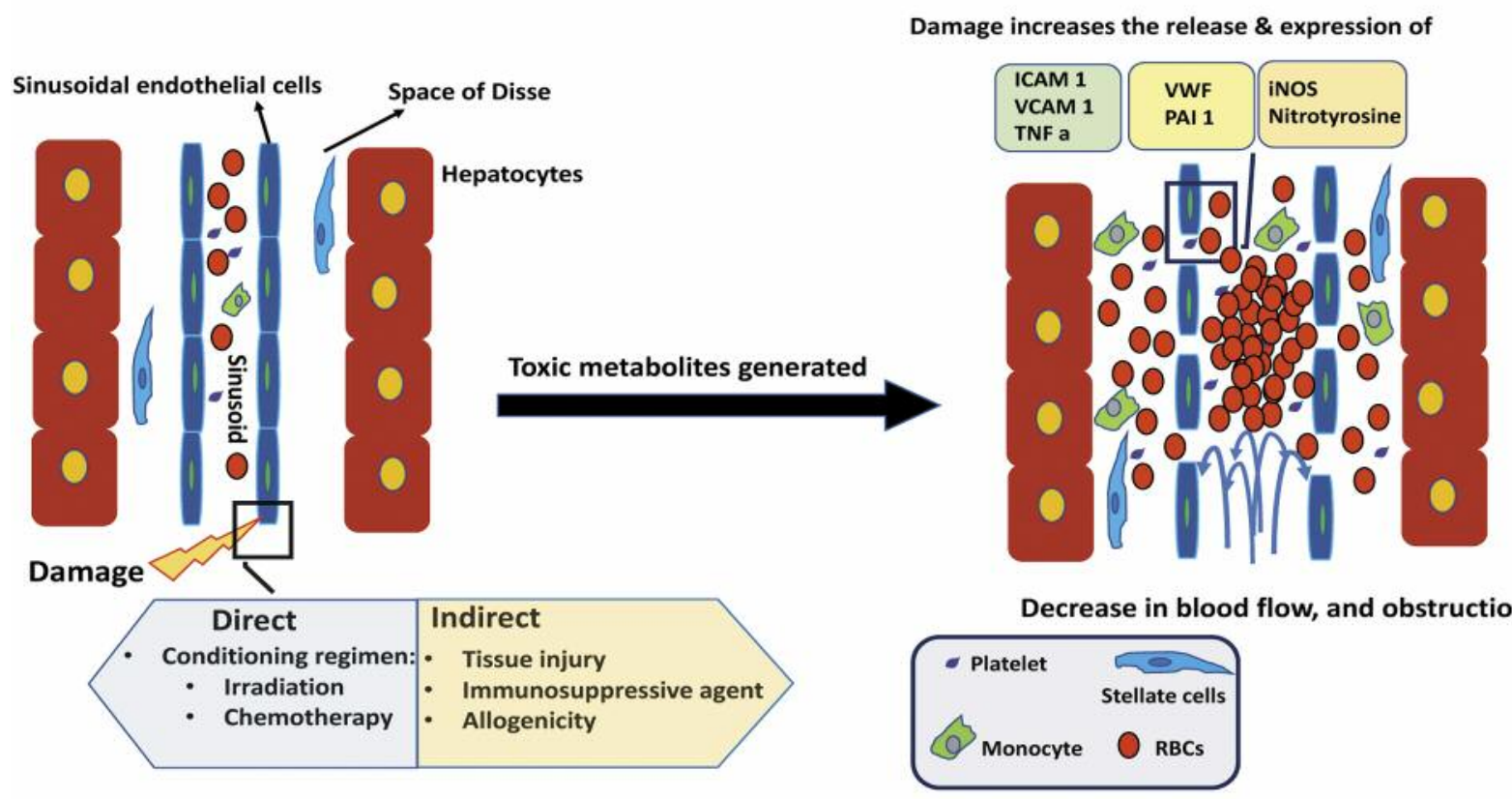

Figure 2. Snusoidal obstruction syndrome (SOS) pathogenesis. Left: Normal blood flow with intact sinusoidal endothelial cells. Right: Sinusoidal endothelial cells damaged by direct and indirect factors. The damage promotes the appearance of gaps in the sinusoidal barrier. Red blood cells $(R B C s)$, platelets and monocytes penetrate the space of Disse due to an increase in the release and expression of cytokine molecules intercellular adhesion molecule-1 (ICAM1), vascular cell adhesion molecule 1 (VCAM1), tumor necrosis factor alpha (TNFa), Von Willebrand factor (VWF), plasminogen activator inhibitor-1 (PAI1), and inducible nitric oxide synthase (iNOS). The endothelial lining consequently detaches. The end result is a decrease in the blood flow, and obstruction, that will lead to embolization and post-sinusoidal hypertension. vWF: Von Willebrand factor; ICAM1: intercellular adhesion molecule-1; PAI1: plasminogen activator inhibitor-1; VEGF: vascular endothelial growth factors; ANG2: angiopoientin2; TNFa: tumor necrosis factor alpha; iNOS: Inducible nitric oxide synthase. VCAM1: Vascular cell adhesion molecule-1. 
SOS. SOS is no longer limited to the 21-day period following transplant. In addition, the typical presence of hyperbilirubinemia is no longer required to make the diagnosis $(6,15)$. A new grading system has been also incorporated classifying cases as mild, moderate, severe, and very severe (6) as outlined in Tables III-V.

Laboratory findings. The laboratory findings are consistent of and not limited to an increase in conjugated bilirubin and transaminases, prolonged prothrombin time, low albumin level and thrombocytopenia, with rapid consumption of transfused platelets $(16,17)$. Given the non-specific laboratory and clinical findings of SOS, other diagnoses should be ruled out such as hyper-acute hepatic GVHD, infection (viral, fungal), cholestasis of sepsis, drug toxicity, biliary obstruction and heart failure (mainly right side) $(10,17)$.

Biomarkers. The use of biomarkers has not been validated as part of the diagnostic criteria of SOS. As previously described above, SOS is associated with an increased expression and release of circulating markers as shown in Table I. Although PAI1 was reported by two studies as a useful diagnostic and prognostic biomarker $(12,18)$, to date, the use of this biomarker has not been integrated into the diagnostic or prognostic tools. More studies are needed to validate the use of biomarkers in the diagnosis of SOS.

Imaging. Imaging modalities such as Doppler ultrasound, computed tomography, and magnetic resonance can be helpful in narrowing the differential diagnosis, especially Doppler ultrasound. There are no sensitive or specific diagnostic findings in SOS. The imaging studies can be helpful to assess the severity of the disease and treatment response by checking the portal vein flow, waveforms, size of liver, and ascites $(10,16,19)$.

Biopsy. Due to the high complication rate of transjugular liver biopsy, it is usually reserved for suspected unclear cases of SOS $(14,17)$. In the early stages of the disease, the histological features of SOS consist of dilation of sinusoids with engorgement due to red blood cells escaping through the space of Disse. This is associated with hepatocyte necrosis in the perivenular area of the liver as illustrated in Figure 2 (3). At a later stage of SOS, liver biopsy reveals incomplete to complete fibrous obliteration of the lumina of central venules with centrilobular area fibrosis that is due to fibrinogen deposition as part of the healing mechanism $(20,21)$.

\section{Risk Factors}

Knowing the risk factors of SOS is critical to help identify the susceptible patients and help clinicians take measures in order to reduce the incidence of this fatal condition $(10,22)$.
Table IV. Grading of sinusoidal obstruction syndrome (SOS) $(10,16,17)$.

\begin{tabular}{|c|c|c|c|}
\hline \multirow[t]{2}{*}{ Parameter } & \multicolumn{3}{|c|}{ SOS grade } \\
\hline & Mild & Moderate & Severe \\
\hline Bilirubin (mg/dl) & $2.0-3.0$ & $3.1-5.0$ & $>5.0$ \\
\hline Liver function & $<3 \times$ Normal & $3-5 \times$ Normal & $>5 \times$ Normal \\
\hline Weight above baseline & $2 \%$ & $2.1 \%-5 \%$ & $>5 \%$ \\
\hline Renal function & Normal & $<2 \times$ normal & $\geq 2 \times$ normal \\
\hline Rate of change & $\begin{array}{l}\text { Slow (over } \\
\text { 6-7 days) }\end{array}$ & $\begin{array}{l}\text { Moderate (over } \\
4-5 \text { days) }\end{array}$ & $\begin{array}{l}\text { Rapid (over } \\
\text { 2-3 days) }\end{array}$ \\
\hline
\end{tabular}

Several studies have looked into predisposing factors associated with the development of SOS. The risk factors can be divided into pre-transplantation and transplantation factors. Table VI provides a detailed list of these factors.

Despite epidemiological studies showing similar incidence of SOS in pediatric and adult populations, the risk of SOS seems to be higher among pediatric patients, particularly those under the age of 7 years. In addition, older patients with lowperformance status have higher incidence of SOS $(23,24)$.

Most of the studies confirmed that a pre-existing liver condition poses a significant risk, where the risk of developing SOS is three to 10 times greater in patients with an elevated serum aspartate aminotransferase AST level, and greater AST elevation correlates with a higher incidence of severe SOS regardless of underlying liver disease $(25,26)$.

The type and severity of the underlying disease determines the likelihood of developing SOS, with more aggressive disease posing an increased risk (26).

Increased risk for SOS is also seen in patients with underlying genetic predisposition such as those with glutathione-S-transferase M1 (GSTM1-null) genotype, $\mathrm{C} 282 \mathrm{Y}$ hemochromatosis allele, and methyl hydrofolate reducatse (MTHFR )677CC/1298CC haplotype (27-29).

Other risk factors are related to the transplant process such as the type of conditioning regimen and the source of graft. The risk is higher in patients receiving matched unrelated and non T-cell-depleted grafts (10, 30-36). Patients who have undergone SCT and patients who received abdominal radiation prior to HSCT are at higher risk of SOS $(24,26)$. Using high-dose total body irradiation of more than $12 \mathrm{~Gy}$ with cyclophosphamide as part of myeloablative therapy relatively increases the risk for SOS (32-34). It was found that delay of transplantation for more than 12 months after diagnosis may also increase the risk for $\operatorname{SOS}(32,33)$.

Many drugs have been implicated in the development of SOS, Prophylactic GVHD regimens using cyclosporine A, sirolimus, and methotrexate have been reported to increase the risk for SOS as these drugs promote EC damage $(28,34$, 37). The risk of SOS with the use of busulfan is dependent 
Table V. New criteria of the European Society for Blood and Marrow Transplantation for severity grading of sinusoidal obstruction syndrome (SOS) (2).

\begin{tabular}{|c|c|c|c|c|}
\hline \multirow[t]{2}{*}{ Parameter } & \multicolumn{4}{|c|}{ SOS grade } \\
\hline & Mild & Moderate & Severe & Very severe MOD/MOF \\
\hline Time since 1st clinical symptoms of SOS, days & $>7$ & $5-7$ & $\leq 4$ & Any time \\
\hline Bilirubin, mg/dl & $\geq 2$ And $<3$ & $\geq 3$ And $<5$ & $\geq 5$ And $<8$ & $\geq 8$ \\
\hline Bilirubin kinetics & & Doubling within $48 \mathrm{~h}$ & & \\
\hline Transaminases & $\leq 2 \times$ Normal & $>2$ And $\leq 5 \times$ normal & $\geq 5$ And $\leq 8 \times$ normal & $>8 \times$ Normal \\
\hline Weight increase & $<5 \%$ & $\geq 5 \%$ And $<10 \%$ & $\geq 5 \%$ And $<10 \%$ & $\geq 10 \%$ \\
\hline Renal function & $\begin{array}{c}<1.2 \times \text { Baseline } \\
\text { at transplant }\end{array}$ & $\begin{array}{c}\geq 1.2 \text { And }<1.5 \times \text { baseline } \\
\text { at transplant }\end{array}$ & $\begin{array}{c}\geq 1.5 \text { And }<2 \times \text { baseline } \\
\text { at transplant }\end{array}$ & $\begin{array}{l}\quad \geq 2 \times \text { Baseline } \\
\text { at transplant or other } \\
\text { signs of MOD/MOF }\end{array}$ \\
\hline
\end{tabular}

MOD: Multi-organ dysfunction; MOF: multi-organ failure.

on the drug pharmacodynamics. It has been shown that the risk is lower with the use of intravenous busulfan with pharmacodynamic monitoring. SOS developed in six out of 18 patients with an initial area under the curve of greater than $1,500 \mathrm{nM} \mathrm{min} / 1$ compared with only one out of 33 patients with a lower area under the curve (38).

Despite the great benefit of targeted therapy, with an overall lower toxicity profile, whereas bevacizumab may have a protective effect against SOS, the risk for SOS is greatest with the other humanized monoclonal antibody to CD33 gemtuzumab ozogamicin (GO) and the humanized monoclonal antibody to CD22 inotuzumab ozogamicin (INO) $(39,40)$. In postmarketing data, the incidence of SOS and fatal hepatotoxicity increased with the use of GO, which led to its removal from the market in 2010 (40-44). Nevertheless, GO has been back in market after regaining approval for use in patients with relapsed/refractory acute myeloid leukemia or as frontline therapy in patients with CD33-positive acute myeloid leukemia. The risk for SOS after INO therapy is increased compared with conventional chemotherapy according to a phase 3 trial (45).

\section{Prevention and Treatment}

SOS is associated with high mortality and morbidity. Although many of the factors predisposing to SOS are difficult to control, physicians should optimize the patient's status including adequate hydration and medication reconciliation. Closer monitoring should be offered for highrisk patients. Addressing underlying hepatitis and match compatibilities prior to transplant, and adjusting the conditioning regimen are ways to help reduce SOS risk.

The treatment varies according to the severity of the disease. Mild disease is usually self-limited and requires no treatment. Supportive care is the first intervention offered to provide symptomatic relief by managing the volume overload and the associated electrolyte disturbances. Seventy-five to $80 \%$ of cases of SOS are reversible with the use of supportive measures alone (17). However, there is still an unmet need to provide a better outcome in patients with severe disease. Several preventive options and treatment strategies have been explored.

\section{Prevention}

Ursodeoxycholic acid (UDCA). Several studies have looked into the efficacy of UDCA in preventing SOS and hepatic GVHD, although the results were not consistent in all of the studies. The largest randomized study conducted by Rutuu et al. (46) failed to show a reduction in the incidence of SOS, the other two studies showed a reduction in both the incidence of SOS and grade 3 acute hepatic GVHD and better 1-year survival $(47,48)$. As result, UDCA has been included in the transplant guidelines to be used as prophylactic agent for SOS in patients undergoing allogeneic HSCT. The suggested doses of UDCA are either a total daily dose of 12 $\mathrm{mg} / \mathrm{kg}$ or fixed dose of $600 \mathrm{mg}$ divided into two doses, to be given from the day preceding the preparative regimen and continued for the first 3 months of transplantation. UDCA prophylaxis is well tolerated with limited side-effects (46-48).

Heparin and low molecular weight heparin. The potential benefit of prophylactic heparin or low molecular weight heparin in the transplant process is limited given the absence of sufficient studies. Two randomized controlled trials evaluated heparin for hepatic SOS prophylaxis but the results were not consistent $(49,50)$. It is suggested that patients undergoing autologous HSCT receive low-dose heparin (100 units/kg per day by continuous intravenous infusion) to be started the first day of the preparative regimen and continued until hematopoietic engraftment $(51,52)$. 
Table VI. Risk factors associated with development of sinusoidal obstruction syndrome $(6,10,22-24,30-36)$.

Pre-transplantation factors

Patient-related:

- Age.

- Underlying disease or malignancy: MDS, leukemia,

CML, immunodeficiency, thalassemia.

- Worsen health status within 30 days before transplantation:

Fever, diarrhea, and nutrition status (Ped).

- Poor performance status (Karnofsky score<90\%).

- Metabolic syndrome.

- Previously treatment with norethisterone, progestin (Adult).

Disease-related:

- Advanced disease.

- Previous stem cell transplantation.

- Genetic: GSTM1.

- Infection/antibiotic/antiviral use (Ped).

- Prior abdominal radiation (Adult).

- >12 Months between diagnosis of malignancy and

transplantation (Ped).

- Impaired pulmonary function (Adult).

Hepatic-related:

- Pre-existing liver disease: hepatitis, CMV.

- Bilirubin $>26 \mu \mathrm{mol} / 1$ Before HSCT.

- Ferritin level>1000 ng/ml (Ped).

- Increased transaminase.

- Previously treated with gemtuzumab, ozogamicin.

- Cirrhosis, hepatic fibrosis.

Transplantation factors

- Allogeneic > autologous HSCT.

- GVHD prophylaxis:

Sirolimus+ Tacrolimus+ Methotrexate

Methotrexate + Cyclosporine

Cyclosporine

- Unrelated donor/HLA mismatch.

- High-dose/myeloablative therapy: a combination of the condition regimens.

- High-dose total body irradiation: >12 Gy+ cyclophosphamide.

- Non-T-cell-depleted graft (Ped).

- Acute hepatic/gut GVHD (Ped).

HSCT: Hematopoietic stem cell transplant; CMV: cytomegalovirus; MDS: myelodysplastic syndromes; CML: chronic myeloid leukemia. (Ped): pediatric More evident in the pediatric population $v s$. adult. (Adult): more evident in the adult population $v s$. pediatric.

\section{Treatment}

It is important to note that treatment is tailored according to the severity of the disease. Mild grade disease is usually limited and reversible by supportive management. However, more aggressive disease requires for prompt pharmacological intervention. Although many agents have been tried (including tissue plasminogen activator and steroids), none of these have shown any efficacy.
Defibrotide is the only medication approved by the FDA for the treatment of SOS. Defibrotide is sodium salt of complex single-stranded oligodeoxyribonucleotides derived from porcine mucosal DNA. It is thought that defibrotide has an endothelial protective role and helps the restoration of the thrombotic-fibrinolytic balance, yet the full mechanism of action is poorly defined. It has both antiinflammatory and anticoagulant activities. It increases the level of tissue plasminogen activator, thus increasing fibrinolysis $(53,54)$. Defibrotide is included in the guidelines as the only therapeutic pharmacologic agent for SOS but it has not yet been approved as a prophylactic treatment. In March 2016, The FDA approved Defitelio (defibrotide sodium) for the treatment of adult and pediatric patients with hepatic SOS, with renal or pulmonary dysfunction following HSCT (55). The approval was based on the result of three studies evaluating the efficacy of defibrotide sodium in a total of 528 patients. The survival rates on day 100 of therapy were $38 \%$ (95\% confidence interval $=29-48 \%), 44 \%$ ( $95 \%$ confidence interval $=33-55 \%)$ and $45 \%(95 \%$ confidence interval $=40-51 \%)$ for each of the studies, respectively (56-58). Based on published reports and analyses of patient-level data, the day 100 survival rates were $21 \%$ to $31 \%$ for patients with hepatic SOS with renal or pulmonary dysfunction who received supportive care or interventions other than defibrotide sodium. The medication was overall well tolerated with hypotension, diarrhea, vomiting, nausea, and epistaxis being the most common noted adverse reactions. The recommended dose and schedule for defibrotide sodium is $6.25 \mathrm{mg} / \mathrm{kg}$ intravenously every 6 hours given as a 2-hour infusion for at least 21 days, and continued until SOS resolution or up to 60 days of treatment (59).

\section{Conclusion}

SOS is one of the most dreadful complications of HSCT. Contrary to initial belief, sinusoidal obstruction is not the result of a thrombotic event, but is related to the occlusion of hepatic venules by necrotic cells as a result of an endothelial damage triggered by an inflammatory cascade following toxic injury to hepatic venules. Few preventive measures can be taken, with UDCA to be used in allogeneic HSCT and lowdose heparin in autologous HSCT. Defibrotide is the only medication approved for the treatment of SOS. Physician awareness of predisposing factors and serious attempts to minimize these risks should help reduce the incidence of severe disease.

\section{Conflicts of Interest}

The Authors declare that they have no financial relationship with any entity and that this article is a reflection of their own work. This article was written in compliance with all ethical standards. 


\section{References}

1 Mcdonald GB, Sharma P, Matthews DE, Shulman HM and Thomas ED: Venocclusive disease of the liver after bone marrow transplantation: diagnosis, incidence and predisposing factors. Hepatology 4: 116-122, 1984.

2 Mohty M, Malard F, Abecassis M, Aerts E, Alaskar A, Aljurf M, Arat M, Bader P, Baron F and Bazarbachi A: Revised diagnosis and severity criteria for sinusoidal obstruction syndrome/veno-occlusive disease in adult patients: a new classification from the European Society for Blood and Marrow Transplantation. Bone marrow transplantation 51: 906-912, 2016.

3 Vion A-C, Rautou P-E, Durand F, Boulanger CM and Valla DC: Interplay of inflammation and endothelial dysfunction in bone marrow transplantation: focus on hepatic veno-occlusive disease. In: Seminars in thrombosis and hemostasis: Thieme Medical Publishers, pp. 629-643, 2015.

4 DeLeve LD: Cellular target of cyclophosphamide toxicity in the murine liver: role of glutathione and site of metabolic activation. Hepatology 24: 830-837, 1996.

5 Wolf C, Moll E, Friedberg T, Oesch F, Buchmann A, Kuhlmann W and Kunz H: Characterization, localization and regulation of a novel phenobarbital-inducible form of cytochrome P450, compared with three further P450-isoenzymes, NADPH P450reductase, glutathione transferases and microsomal epoxide hydrolase. Carcinogenesis 5: 993-1001, 1984.

6 Mohty M, Malard F, Abecassis M, Aerts E, Alaskar A, Aljurf M, Arat M, Bader P, Baron F and Bazarbachi A: Sinusoidal obstruction syndrome/veno-occlusive disease: current situation and perspectives - a position statement from the European Society for Blood and Marrow Transplantation (EBMT). Bone marrow transplantation 50: 781-789, 2015.

7 Eissner G, Multhoff $\mathrm{G}$ and Holler E: Influence of bacterial endotoxin on the allogenicity of human endothelial cells. Bone marrow transplantation 21: 1286-1288, 1998.

8 Palomo M, Diaz-Ricart M, Carbo C, Rovira M, FernandezAviles F, Martine C, Ghita G, Escolar G and Carreras E: Endothelial dysfunction after hematopoietic stem cell transplantation: role of the conditioning regimen and the type of transplantation. Biol of Blood and Marrow Transplant 16: 985 993, 2010

9 Coppell JA, Richardson PG, Soiffer R, Martin PL, Kernan NA, Chen A, Guinan E, Vogelsang G, Krishnan A and Giralt S: Hepatic veno-occlusive disease following stem cell transplantation: incidence, clinical course and outcome. Biol of Blood and Marrow Transplant 16: 157-168, 2010.

10 Dalle J-H and Giralt SA: Hepatic veno-occlusive disease after hematopoietic stem cell transplantation: risk factors and stratification, prophylaxis and treatment. Biol of Blood and Marrow Transplant 22: 400-409, 2016.

11 Strasser SI, Shulman HM, Flowers ME, Reddy R, Margolis DA, Prumbaum M, Seropian SE and McDonald GB: Chronic graftversus-host disease of the liver: Presentation as an acute hepatitis. Hepatology 32: 1265-1271, 2000.

12 Salat C, Holler E, Kolb HJ, Pihusch R, Reinhardt B, Penovici $\mathrm{M}$, Ledderose $\mathrm{G}$ and Miller E: The relevance of plasminogen activator inhibitor 1 (PAI-1) as a marker for the diagnosis of hepatic veno-occlusive disease in patients after bone marrow transplantation. Leuk lymphoma 33: 25-32, 1999.
13 Nürnberger W, Michelmann I, Burdach S and Göbel U: Endothelial dysfunction after bone marrow transplantation: increase of soluble thrombomodulin and PAI-1 in patients with multiple transplant-related complications. Ann Hematol 76: 6165, 1998.

14 Jones RJ, Lee KS, Beschorner WE, Vogel VG, Grochow LB, Braine HG, Vogelsang GB, Sensenbrenner LL, Santos GW and Saral R: Venoocclusive disease of the liver following bone marrow transplantation. Transplantation 44: 778-783, 1987.

15 Myers KC, Dandoy C, El-Bietar J, Davies SM and Jodele S: Venoocclusive disease of the liver in the absence of elevation in bilirubin in pediatric patients after hematopoietic stem cell transplantation. Biol of Blood Marrow Transplant 21: 379-381, 2015.

16 Chao N: How I treat sinusoidal obstruction syndrome. Blood 123: 4023-4026, 2014.

17 Carreras E: How I manage sinusoidal obstruction syndrome after haematopoietic cell transplantation. Br J Haematol 168: 481-491, 2015.

18 Park Y, Yasui M, Yoshimoto T, Chayama K, Shimono T, Okamura T, Inoue M, Yumura-Yagi K and Kawa-Ha K: Changes in hemostatic parameters in hepatic veno-occlusive disease following bone marrow transplantation. Bone Marrow Transplant 19: 915-920, 1997.

19 Dignan FL, Wynn RF, Hadzic N, Karani J, Quaglia A, Pagliuca A, Veys $\mathrm{P}$ and Potter MN: BCSH/BSBMT guideline: diagnosis and management of veno-occlusive disease (sinusoidal obstruction syndrome) following haematopoietic stem cell transplantation. Br J Haematol 163: 444-457, 2013.

20 Sato Y, Asada Y, Hara S, Marutsuka K, Tamura K, Hayashi T and Sumiyoshi A: Hepatic stellate cells (Ito cells) in venoocclusive disease of the liver after allogeneic bone marrow transplantation. Histopathology 34: 66-70, 1999.

21 Shulman HM, McDonald GB, Matthews D, Doney KC, Kopecky KJ, Gauvreau JM and Thomas ED: An analysis of hepatic venocclusive disease and centrilobular hepatic degeneration following bone marrow transplantation. Gastroenterology 79: 1178-1191, 1980.

22 Yakushijin K, Atsuta Y, Doki N, Yokota A, Kanamori H, Miyamoto T, Ohwada C, Miyamura K, Nawa Y, Kurokawa M, Mizuno I, Mori T, Onizuka M, Taguchi J, Ichinohe T, Yabe H, Morishima Y, Kato K, Suzuki R and Fukuda T: Sinusoidal obstruction syndrome after allogeneic hematopoietic stem cell transplantation: Incidence, risk factors and outcomes. Bone Marrow Transplant 51: 403-409, 2016.

23 Tsirigotis PD, Resnick IB, Avni B, Grisariu S, Stepensky P, Or $\mathrm{R}$ and Shapira MY: Incidence and risk factors for moderate-tosevere veno-occlusive disease of the liver after allogeneic stem cell transplantation using a reduced intensity conditioning regimen. Bone Marrow Transplant 49: 1389-1392, 2014.

24 Maximova N, Ferrara G, Minute M, Pizzol A, Kiren V, Montico M, Gregori $M$ and Tamaro P: Experience from a single paediatric transplant centre with identification of some protective and risk factors concerning the development of hepatic venoocclusive disease in children after allogeneic hematopoietic stem cell transplant. Int J Hematol 99: 766-772, 2014.

25 McDonald GB, Hinds MS, Fisher LD, Schoch HG, Wolford JL, Banaji M, Hardin BJ, Shulman HM and Clift RA: Venoocclusive disease of the liver and multiorgan failure after bone marrow transplantation: a cohort study of 355 patients. Ann Intern Med 118: 255-267, 1993. 
26 Carreras E, Bertz H, Arcese W, Vernant J-P, Tomás J-F, Hagglund $\mathrm{H}$, Bandini $\mathrm{G}$, Esperou $\mathrm{H}$, Russell $\mathrm{J}$ and de la Rubia $\mathrm{J}$ : Incidence and outcome of hepatic veno-occlusive disease after blood or marrow transplantation: a prospective cohort study of the European Group for Blood and Marrow Transplantation. Blood 92: 3599-3604, 1998.

27 Srivastava A, Poonkuzhali B, Shaji RV, George B, Mathews V, Chandy $\mathrm{M}$ and Krishnamoorthy R: Glutathione S-transferase M1 polymorphism: a risk factor for hepatic venoocclusive disease in bone marrow transplantation. Blood 104: 1574-1577, 2004.

28 Efrati E, Zuckerman T, Ben-Ami E and Krivoy N: MTHFR C677T/A1298C genotype: a possible risk factor for liver sinusoidal obstruction syndrome. Bone Marrow Transplant 49: 726, 2014.

29 Kallianpur AR, Hall L, Yadav M, Byrne D, Speroff T, Dittus R, Haines J, Christman B and Summar M: The hemochromatosis C282Y allele: a risk factor for hepatic veno-occlusive disease after hematopoietic stem cell transplantation. Bone Marrow Transplant 35: 1155-1164, 2005.

30 Dulley FL, Kanfer EJ, Appelbaum FR, Amos D, Hill RS, Buckner CD, Shulman HM, McDonald GB and Thomas ED: Venocclusive disease of the liver after chemoradiotherapy and autologous bone marrow transplantation. Transplantation 43: 870-873, 1987.

31 Carreras E, Rosinol L, Terol MJ, Alegre A, de Arriba F, GarciaLarana J, Bello JL, Garcia R, Leon A, Martinez R, Penarrubia MJ, Poderos C, Ribas P, Ribera JM, San Miguel J, Blade J and Lahuerta JJ: Veno-occlusive disease of the liver after high-dose cytoreductive therapy with busulfan and melphalan for autologous blood stem cell transplantation in multiple myeloma patients. Biol Blood Marrow Transplant 13: 1448-1454, 2007.

32 Cheuk D, Wang P, Lee T, Chiang A, Ha S, Lau Y and Chan G: Risk factors and mortality predictors of hepatic veno-occlusive disease after pediatric hematopoietic stem cell transplantation. Bone Marrow Transplant 40: 935-944, 2007.

33 Barker CC, Butzner J anderson R, Brant R and Sauve R: Incidence, survival and risk factors for the development of venoocclusive disease in pediatric hematopoietic stem cell transplant recipients. Bone Marrow Transplant 32: 79-87, 2003.

34 Moscardó F, Urbano-Ispizua Á, Sanz GF, Brunet S, Caballero D, Vallejo C, Solano C, Pimentel P, de Oteyza JP and Ferrá C: Positive selection for $\mathrm{CD} 34+$ reduces the incidence and severity of veno-occlusive disease of the liver after HLA-identical sibling allogeneic peripheral blood stem cell transplantation. Exp Hematol 31: 545-550, 2003.

35 Hogan WJ, Maris M, Storer B, Sandmaier BM, Maloney DG, Schoch HG, Woolfrey AE, Shulman HM, Storb R and McDonald GB: Hepatic injury after nonmyeloablative conditioning followed by allogeneic hematopoietic cell transplantation: a study of 193 patients. Blood 103: 78-84, 2004.

36 Carreras E: Hepatic veno-occlusive disease following haematopoietic cell transplantation: pathogenesis, diagnosis, risk factors, prophylaxis and treatment VOD following cell transplantation. Hematology 3: 109-113, 2013.

37 Cutler C, Stevenson K, Kim HT, Richardson P, Ho VT, Linden E, Revta C, Ebert R, Warren D, Choi S, Koreth J, Armand P, Alyea E, Carter S, Horowitz M, Antin JH and Soiffer R: Sirolimus is associated with veno-occlusive disease of the liver after myeloablative allogeneic stem cell transplantation. Blood 112: 4425-4431, 2008
38 Lee JH, Choi SJ, Lee JH, Kim SE, Park CJ, Chi HS, Lee MS, Lee JS, Kim WK and Lee KH: Decreased incidence of hepatic veno-occlusive disease and fewer hemostatic derangements associated with intravenous busulfan $v s$. oral busulfan in adults conditioned with busulfan + cyclophosphamide for allogeneic bone marrow transplantation. Ann Hematol 84: 321-330, 2005.

39 Arakawa Y, Shimada M, Utsunomiya T, Imura S, Morine Y, Ikemoto T, Hanaoka J, Kanamoto M, Iwahashi S, Saito Y, Yamada S, Asanoma M, Takasu C And Bando Y: Bevacizumab Improves Splenomegaly and Decreases Production of Hyaluronic Acid After L-OHP Based Chemotherapy. Anticancer Res 34: 1953-1958, 2014.

40 Nishigori N, Matsumoto M, Koyama F, Hayakawa M, Hatakeyayama K, Ko S, Fujimura Y and Nakajima Y: von Willebrand factor-rich platelet thrombi in the liver cause sinusoidal obstruction syndrome following oxaliplatin-based chemotherapy. PLoS ONE 10: e0143136, 2015.

41 Wadleigh M, Richardson PG, Zahrieh D, Lee SJ, Cutler C, Ho V, Alyea EP, Antin JH, Stone RM, Soiffer RJ and DeAngelo DJ: Prior gemtuzumab ozogamicin exposure significantly increases the risk of veno-occlusive disease in patients who undergo myeloablative allogeneic stem cell transplantation. Blood 102: 1578-1582, 2003.

42 Rajvanshi P, Shulman HM, Sievers EL and McDonald GB: Hepatic sinusoidal obstruction after gemtuzumab ozogamicin (Mylotarg) therapy. Blood 99: 2310-2314, 2002.

43 Tallman MS, McDonald GB, DeLeve LD, Baer MR, Cook MN, Graepel GJ and Kollmer C: Incidence of sinusoidal obstruction syndrome following Mylotarg (gemtuzumab ozogamicin): a prospective observational study of 482 patients in routine clinical practice. Int J Hematol 97: 456-464, 2013.

44 Giles FJ, Kantarjian HM, Kornblau SM, Thomas DA, GarciaManero G, Waddelow TA, David CL, Phan AT, Colburn DE, Rashid A and Estey EH: Mylotarg (gemtuzumab ozogamicin) therapy is associated with hepatic venoocclusive disease in patients who have not received stem cell transplantation. Cancer 92: 406-413, 2001.

45 Kantarjian HM, DeAngelo DJ, Stelljes M, Martinelli G, Liedtke M, Stock W, Gökbuget N, O'Brien S, Wang K, Wang T, Paccagnella ML, Sleight B, Vandendries E and Advani AS: Inotuzumab ozogamicin versus standard therapy for acute lymphoblastic leukemia. NEJM 375: 740-753, 2016.

46 Ruutu T, Eriksson B, Remes K, Juvonen E, Volin L, Remberger M, Parkkali T, Hagglund $\mathrm{H}$ and Ringden O: Ursodeoxycholic acid for the prevention of hepatic complications in allogeneic stem cell transplantation. Blood 100: 1977-1983, 2002.

47 Essell JH, Schroeder MT, Harman GS, Halvorson R, Lew V, Callander N, Snyder M, Lewis SK, Allerton JP and Thompson JM: Ursodiol prophylaxis against hepatic complications of allogeneic bone marrow transplantation. A randomized, double-blind, placebocontrolled trial. Ann Intern Med 128: 975-981, 1998.

48 Ohashi K, Tanabe J, Watanabe R, Tanaka T, Sakamaki H, Maruta A, Okamoto S, Aotsuka N, Saito K, Nishimura M, Oh H, Matsuzaki M, Takahashi S and Yonekura S: The Japanese multicenter open randomized trial of ursodeoxycholic acid prophylaxis for hepatic veno-occlusive disease after stem cell transplantation. Am J Hematol 64: 32-38, 2000.

49 Tay J, Tinmouth A, Fergusson D, Huebsch L and Allan DS: Systematic review of controlled clinical trials on the use of ursodeoxycholic acid for the prevention of hepatic venoocclusive disease in hematopoietic stem cell transplantation. Biol Blood Marrow Transplant 13: 206-217, 2007. 
50 Cheuk DK, Chiang AK, Ha SY and Chan GC: Interventions for prophylaxis of hepatic veno-occlusive disease in people undergoing haematopoietic stem cell transplantation. Cochrane database Sys Rev 5: CD009311, 2015.

51 Imran H, Tleyjeh IM, Zirakzadeh A, Rodriguez V and Khan SP: Use of prophylactic anticoagulation and the risk of hepatic venoocclusive disease in patients undergoing hematopoietic stem cell transplantation: a systematic review and meta-analysis. Bone Marrow Transplant 37: 677-686, 2006.

52 Attal M, Huguet F, Rubie H, Huynh A, Charlet JP, Payen JL, Voigt JJ, Brousset P, Selves J, Muller C and et al.: Prevention of hepatic veno-occlusive disease after bone marrow transplantation by continuous infusion of low-dose heparin: a prospective, randomized trial. Blood 79: 2834-2840, 1992.

53 Benimetskaya L, Wu S, Voskresenskiy AM, Echart C, Zhou J-F, Shin J, Iacobelli M, Richardson P, Ayyanar K and Stein CA: Angiogenesis alteration by defibrotide: implications for its mechanism of action in severe hepatic veno-occlusive disease. Blood 112: 4343-4352, 2008.

54 Zhou Q, Chu X and Ruan C: Defibrotide stimulates expression of thrombomodulin in human endothelial cells. Thromb Haemost 71: 507-510, 1994.

55 http://www.accessdata.fda.gov/drugsatfda_docs/label/2016/ 208114lbl.pdf (Accessed on March 31.

56 Richardson PG, Riches ML, Kernan NA, Brochstein JA, Mineishi S, Termuhlen AM, Arai S, Grupp SA, Guinan EC, Martin PL, Steinbach G, Krishnan A, Nemecek ER, Giralt S Rodriguez T, Duerst R, Doyle J, Antin JH, Smith A, Lehmann L, Champlin R, Gillio A, Bajwa R, D'Agostino RB, Massaro J, Warren D, Miloslavsky M, Hume RL, Iacobelli M, Nejadnik B, Hannah AL, and Soiffer RJ: Phase 3 trial of defibrotide for the treatment of severe veno-occlusive disease and multi-organ failure. Blood 127: 1656-1665, 2016.
57 Richardson PG, Soiffer RJ, Antin JH, Uno H, Jin Z, Kurtzberg J, Martin PL, Steinbach G, Murray KF, Vogelsang GB, Chen AR, Krishnan A, Kernan NA, Avigan DE, Spitzer TR, Shulman HM, Di Salvo DN, Revta C, Warren D, Momtaz P, Bradwin G, Wei LJ, Iacobelli M, McDonald GB, and Guinan EC: Defibrotide for the treatment of severe hepatic veno-occlusive disease and multiorgan failure after stem cell transplantation: a multicenter, randomized, dose-finding trial. Biol Blood Marrow Transplant 16: 1005-1017, 2010.

58 Corbacioglu S, Cesaro S, Faraci M, Valteau-Couanet D, Gruhn B, Rovelli A, Boelens JJ, Hewitt A, Schrum J, Schulz AS, Muller I, Stein J, Wynn R, Greil J, Sykora KW, Matthes-Martin S, Fuhrer M, O’Meara A, Toporski J, Sedlacek P, Schlegel PG, Ehlert K, Fasth A, Winiarski J, Arvidson J, Mauz-Korholz C, Ozsahin H, Schrauder A, Bader P, Massaro J, D'Agostino R, Hoyle M, Iacobelli M, Debatin KM, Peters C, and Dini G: Defibrotide for prophylaxis of hepatic veno-occlusive disease in paediatric haemopoietic stem-cell transplantation: an open-label, phase 3, randomised controlled trial. Lancet 379: 1301-1309, 2012.

59 Palo Alto CJP: Defitelio (defibrotide sodium) [package insert]. March 30, 2016. https://www.accessdata.fda.gov/drugsatfda_ docs/label/2016/208114lbl.pdf
Received January 20, 2018

Revised March 4, 2018

Accepted March 7, 2018 